\title{
Da Esquina Ao Escritório: Uma Análise Sobre A Ausência De Mulheres Transexuais No Mercado De Trabalho Formal Em Goiás*
}

De la esquina a la oficina: un análisis sobre la ausencia de mujeres transgénero en el mercado laboral formal en goiás

\section{From The Corner To The Office: An Analysis Of The Absence Of Transgender Women In The} Formal Labor Market In Goiás

DOI: https://doi.org/10.21803/penamer.13.26.419

João Vitor Rodrigues Gonçalves

https://orcid.org/0000-0001-8704-664X

Ricardo Antonio Simancas Trujillo

https://orcid.org/0000-0002-3937-8356

\section{¿Cómo citar este artículo?}

Rodrigues, J. \& Simancas, R. (2020). Da Esquina Ao Escritório: Uma Análise Sobre A Ausência De Mulheres Transexuais No Mercado De Trabalho Formal Em Goiás. Pensamiento Americano, 13(26), 33-50.

DOI: https://doi.org/10.21803/penamer.13.26.419

\begin{abstract}
Resumo
O objetivo deste estudo é analisar a ausência de mulheres transexuais nas organizações, pautando-se em depoimentos que buscam sintetizar a relação existente entre as transexuais e o mundo do trabalho em Goiás. Pretendeu-se dar visibilidade as principais dificuldades encontradas pelas transexuais ao tentar se inserir no mercado, de modo a contribuir na discussão sobre alternativas que possam promover sua inserção. Os resultados apontam que a escassez de políticas públicas e o despreparo das empresas são considerados os fatores determinantes que reafirmam sua exclusão nos espaços laborais. A abordagem metodológica concentra-se na revisão bibliográfica e na análise documental. Em decorrência da COVID-19, os depoimentos foram construídos de forma virtual, utilizando-se das tecnologias ativas. Em suma, é preciso propor ações que assegurem a participação das transexuais desde a elaboração até a implementação das estratégias empresariais e das políticas públicas que, de fato, proponham à inserção de mulheres transexuais no mercado.
\end{abstract}

Keywords: Identidade de gênero, Mercado, Mulheres transexuais, Trabalho, Organizações.

\section{Resumen}

El objetivo de este estudio es analizar la ausencia de mujeres transexuales en las organizaciones, a partir de testimonios que buscan aunar la relación existente entre los transexuales y el mundo del trabajo en Goiás. Se pretendía dar visibilidad a las principales dificultades que encuentran los transexuales al intentar entrar en el mercado, para contribuir con el debate sobre las alternativas que pueden favorecer su inserción. Los resultados apuntan a que la escasez de políticas públicas y la despreocupación de las empresas se consideran los factores determinantes que reafirman su exclusión en los espacios laborales. El enfoque metodológico se centra en la revisión bibliográfica y en el análisis documental. Como resultado de COVID-19, los testimonios se obtuvieron de forma virtual, utilizando tecnologías activas. En resumen, es necesario proporcionar acciones que aseguren la participación de los transexuales desde la elaboración hasta la implementación de las estrategias empresariales y las 
políticas públicas que, de hecho, proponen la inserción de las mujeres transexuales en el mercado.

Palabras Clave: Identidad de género, Mercado, Mujeres transexuales, Trabajo, Organizaciones.

\begin{abstract}
The aim of this study is to analyze the absence of transsexual women in organizations, based on testimonials that seek to combine the existing relationship between transsexuals and the working world in Goiás. The intention was to give visibility to the main difficulties encountered by transsexuals when trying to enter into the market, in order to contribute to the discussion about alternatives that may promote their insertion. The results indicate that the lack of public policies and the unpreparedness of companies are considered the determining factors that reaffirm their exclusion in the labor market. The methodological approach focuses on literature review and document analysis. As a result of COVID-19, the testimonials were built in a virtual way, using active technologies. In summary, it is necessary to propose actions that ensure the participation of transsexuals from the elaboration to the implementation of business strategies and public policies that could help and guarantee the insertion of transsexual women in the market.

Keywords: Gender identity, Market, transsexual women, Labor, organizations.
\end{abstract}

\title{
Perfiles
}

34 Bacharel em Administração pela Universidade Estadual de Goiás, e-mail: dhc.goianesia@gmail.com.

Doutor pela Universidad para la Cooperación Internacional de México e professor do curso de licenciatura em Educação da Corporación Universitária Americana, e-mail: rasimancas@coruniamericana.edu.co.
João Vitor Rodrigues Gonçalves

Ricardo Antonio Simancas Trujillo 


\section{Introdução}

O presente estudo é parte do resultado de uma pesquisa no qual buscou compreender a ausência de mulheres transexuais no mercado de trabalho formal em Goiás, identificando as principais dificuldades enfrentadas por elas ao tentar se inserir no mercado e, ao mesmo tempo, os efeitos ocasionados pelo preconceito nas suas vidas cotidianas. Embora as discussões sobre gênero e sexualidade tenham se intensificado nos últimos anos nos diversos espaços sociais, sobretudo no ambiente corporativo, a maioria dos indivíduos trans ainda vivem à margem da sociedade em razão da sua identidade de gênero e, em raras exceções, desempenham atividades laborais em postos de trabalho formais.

"Este estudo foi motivado por meio da constatação inédita de um estudo realizado pela ONG OUT NOW ao relatar, em seus resultados, que pessoas trans têm acesso limitado no trabalho, identificando apenas três trabalhadores transexuais entre os 968 trabalhadores LGBTQIAP+ (lésbicas, gays, bissexuais, travestis, transexuais, queers, intersexuais, assexuais/agêneros, pansexuais, entre outros) entrevistados" (Barcellos, 2017, p.24). Sabe-se que há uma inexpressividade do número de mulheres transexuais no mercado formal ao mesmo tempo em que sua predominância concentra-se em atividades informais discriminatoriamente atribuídas em função das suas identidades de gênero (diversão noturna, serviços de estética e atividades domésticas). Embora as transformações no mundo do trabalho sejam evidentes, ainda ocorrem de forma segregada e excludente, de modo a não ser possível a existência de espaço suficiente para todos (Moura \& Lopes, 2017).

Sabe-se que, a escassez de pessoas trans no mercado de trabalho está relacionada, entre tantos outros fatores, a um processo cultural de marginalização social compulsória. Neste processo, os indivíduos são forçados a viver e conviver à margem da sociedade em razão da sua individualidade, privando-se do exercício de seus direitos e deveres civis, incluso as garantias constitucionais fundamentais, a exemplo do acesso a educação, a saúde e ao trabalho. De certo modo, esse processo favorece a manutenção de um ciclo vicioso constituído, sobretudo, de discriminação e preconceito, que reforça os estereótipos associados às transexuais, a exemplo da prostituição, da criminalidade e da marginalidade.

Observou-se que, embora a inclusão de minorias no mercado de trabalho seja um tema passível de preocupação e interesse comum, tanto ao Estado quanto ao segundo setor, poucos avanços foram registrados em relação à inclusão de mulheres trans. Em síntese, ambos ainda não se propuseram a desenvolver ações práticas que possam viabilizar a inserção massiva desses sujeitos nos ambientes corporativos. As tímidas iniciativas que buscam integrar o sujeito transexual no mercado, em sua maioria, partem de programas e movimentos organizados pela própria comunidade, seja por meio de entidades representativas ou de lideranças do segmento.

Pretende-se, com esta pesquisa, contribuir na discussão sobre a temática, de modo a fomentar o desenvolvimento de possíveis iniciativas capazes de promover a reinserção de mulheres transexuais em sociedade por meio do trabalho, com o intuito de ressignificar seu espaço na sociedade. Para fins mais específicos, o trabalho busca dignificar a existência da mulher trans, buscando, com este estudo, romper estigmas e preconceitos historicamente atribuídos a esta comunidade. Por fim, a pesquisa visa "publicizar" seus dilemas cotidianos, através de seus relatos descritos ao longo do trabalho, com o intuito de sensibilizar o leitor sobre as inúmeras dificuldades encontradas no dia a dia desses indivíduos.

\section{Metodologia}

Os fenômenos sociais, em geral, exigem a aplicação de métodos de análise mais minuciosos que sejam capazes de abarcar toda sua pluralidade e 
que, ao mesmo tempo, possibilitem explorar os mais diversos contextos em que possa ser observado. Nesse sentido, a abordagem qualitativa é a mais apropriada para ser utilizada na investigação, uma vezque refina, enfatiza e estuda com maior prudência os processos envolvidos na pesquisa, atentando-se a qualidade das informações e a aproximação das realidades sociais para com a proposta de estudo. Essa pesquisa concentra sua investigação na amostra da população de mulheres transexuais.

Para Souza e Bernardo (2014) o método a ser utilizado estabelece uma certa aproximação dos sujeitos da pesquisa à realidade em que estão inseridos. De acordo com Lüdke e André (1986), poucas temáticas podem ser submetidas a uma análise quantitativa, a exemplo dos problemas que possuem uma natureza de ordem social. Segundo as autoras, esse tipo de pesquisa pouco contribui para uma reflexão acerca dos problemas socioculturais. O estudo sobre a ausência de mulheres transexuais no mercado não pode ser investigado como um campo de estudo imutável ou limitado, é necessário considerá-lo como um tema flexível, repleto de constantes variações conforme os cenários em que seja examinado.

Para isso é necessário aplicar o método campotema, proposto por Spink (2003), que sugere a aproximação do pesquisador junto à pesquisa e seus personagens, de modo a gerar um tumulto conflituoso de argumentos que contribuem para o desenvolvimento da investigação. Segundo o autor, o campo-tema deve ser compreendido como um produto das relações sociais e, portanto, não deve ser associado a uma realidade absoluta do investigador, a fim de construir e ampliar argumentos relevantes para a construção da pesquisa.

Em virtude da pandemia ocasionada pela COVID-19, presente atualmente em quase todos os países do mundo, com foco centrado nos demais países que integram da América Latina, a aplicação do método proposto por Spink se torna inviável por meio das relações semipresenciais para com os sujeitos desta investigação, em respeito às medidas sanitárias recomendadas pela Organização Mundial da Saúde (OMS), pelo Ministério da Saúde do Brasil e demais órgãos de vigilância sanitária.

O presente estudo possui característica de natureza exploratória, que tem como principal objetivo aproximar-se com problema, com intuito de familiariza-lo e contribuir na formulação de possíveis hipóteses (Gerhardt \& Silveira, 2009). A grande maioria das pesquisas exploratórias realiza levantamento bibliográfico, investiga a relação dos sujeitos com o problema de pesquisa e analisa, com prudência, estudos similares publicados para que sirvam de base teórica (Gil, 2007). Utilizase a observação não participante, com processo de comunicação entre pesquisador e sujeitos mediado de forma remota, utilizando as tecnologias ativas para substituir a pesquisa em campo. Para complementar a composição dos aspectos metodológicos desta investigação, aplica-se uma revisão bibliográfica a partir dos diversos materiais que contextualizam temas relacionados à população trans e seus desdobramentos, de modo geral, com o objetivo de contribuir na elaboração do campo teórico e nas análises e discussões da pesquisa. Em suma, este tipo de análise tem o objetivo de reunir informações sobre o problema a ser investigado, de forma a buscar respostas para o mesmo a partir de obras teóricas já publicadas (Fonseca, 2002).

A análise documental é utilizada durante a organização e discussão dos dados durante todo o desenvolvimento da investigação em conjunto com a revisão da literatura de artigos, dissertações, teses, livros e materiais devidamente publicados. Este tipo de análise possui o papel de complementar a fundamentação investigativa, para elucidar, de forma estratégica, as informações contidas em documentos de referência sobre o assunto. Em síntese, a pesquisa documental recorre a fontes mais diversificadas, eximindo-se de tratamento analítico, embasando-se quase sempre em relatórios governamentais, documentos oficiais e similares (Fonseca, 2002). 


\section{Coleta de Dados}

Nessa etapa, os recursos virtuais foram utilizados para estabelecer a comunicação entre o pesquisador e os sujeitos da pesquisa, por meio de um questionário elaborado com a finalidade de obter informações que possam ser aplicados na investigação. Em sua estrutura, foram construídas seções específicas para descrever o objetivo da pesquisa, sua finalidade e a metodologia a ser utilizada, além de exigir o expresso consentimento e o sigilo das informações fornecidas por parte dos sujeitos ao pesquisador.

Todo o processo transcorreu de forma virtual por meio da troca de endereços eletrônicos e mensagens de aplicativos de mensagem. Os nomes utilizados para localizar os sujeitos na pesquisa são condizentes a sua identificação social, preservando, assim, seus nomes verdadeiros. Nathália Espitaleta, Amanda Proença e Melyssa Agnes são as protagonistas dessa pesquisa. O documento foi dividido em duas partes para facilitar a análise e interpretação das informações. Na primeira etapa, buscou-se analisar dados sobre a escolaridade e perfil socioeconômico e profissional. Na segunda etapa, as personagens puderem discorrer livremente sobre questões relacionadas sobre suas experiências profissionais, seu processo de inserção no mercado e as dificuldades encontradas.

\section{Particularidades da Amostra}

Em virtude dos desdobramentos provocados pela COVID-19 e dos efeitos do isolamento social, muitos possíveis participantes alegaram sua indisponibilidade de contribuir para com a pesquisa devido ao seu estado de saúde psicológico debilitado. Para esses sujeitos, que sobrevivem especialmente da informalidade ou da prostituição, a pandemia reconfigurou drasticamente suas fontes de subsistência, impactando, de certo modo, no seu bem estar psicossocial. Para outros, a insegurança ao discorrer sobre o assunto e o medo de uma possível exposição, mesmo que realizada de maneira sigilosa, ainda tornam sua participação incerta.
Para localizar os sujeitos da pesquisa, utilizouse a técnica de referência pessoal, que consiste na indicação de contatos de possíveis participantes que são recomendados por pessoas que possuem um elevado grau de confiança com as personagens. Das três mulheres transexuais entrevistadas, uma reside em Goiânia, seguido pela cidade de Jataí e Goianésia, distribuídas geograficamente nas regiões norte, centro e sul do estado de Goiás. Ambas são adultas, com idades entre 24 e 40 anos, possuem orientação sexual bastante peculiar declarandose respectivamente pansexual, heterossexual e bissexual. Duas possuem ensino médio completo e uma já finalizou a graduação e possui nacionalidade colombiana.

Atualmente, todas as entrevistadas vivem sozinhas e, de forma coincidente, no passado já recorreram à prostituição como principal atividade laboral para obtenção de renda. Ocupam cargos de assessora de cultura, caixa de hipermercado e atendente de call center e se sentem satisfeitas em relação ao trabalho que desenvolvem. De maneira unânime, relatam que não desejam retornar ao trabalho sexual, mas reconhecem que as atividades noturnas são economicamente mais vantajosas. Possuem rendimentos entre um e três salários mínimos, o que as impossibilita, muitas vezes, de ocupar posições de destaque que ofereçam visibilidade e reconhecimento profissional.

Concordam ao afirmar que as organizações não estãopreparadaspararecebertransexuais, tampouco para integrá-las como parte de seus colaboradores. Uma delas inclusive relata que participou de um processo seletivo socialmente como homem cisgênero e ao se apresentar no departamento de pessoal como mulher trans não foi contratada. Define-se o termo "cisgênero" associado aos padrões cisgêneros, que pode ser compreendido como um conjunto de hábitos, costumes e comportamentos de pessoas cuja identidade de gênero coincide com o sexo biológico anatomicamente constituído. $\mathrm{Ou}$ seja, esse termo expressa a condição de pessoas que mantêm a identidade de gênero a elas atribuída 
ao nascer (Almeida \& Vasconcellos, 2018). Em sua maioria, também podem ser popularmente conhecidos como padrões heteronormativos, ou seja, um conjunto de condutas, hábitos, comportamentos e valores socioculturais exclusivo dos indivíduos heterossexuais.

Por fim, as personagens, também de modo conjunto, creem que o Estado deveria intervir no problema de ordem social e propor soluções capazes de inseri-las no mercado, seja através das políticas públicas ou de estratégias empresariais lideradas pelo segundo setor.

\section{Referencial Téorico}

\section{Breves Discussões Sobre Gênero $E$ Transexualidade}

A identidade de gênero se traduz na percepção íntima que cada indivíduo possui em relação ao gênero ao qual se identifica independente do seu sexo biológico (Barcellos, 2017) e se refere, sobretudo, a compreensão que alguém tem de si próprio em relação às suas características biopsíquicas e construções socioculturais, podendo ser classificadas como masculinas, femininas ou ambivalentes (Rondas \& Machado, 2015). Ocasionalmente, a identidade de gênero do sujeito pode não estar alinhada com o sexo que lhe foi atribuído, dando origem a questionamentos sobre a transexualidade (Organização das Nações Unidas no Brasil [ONUBR], 2018). Para compreender este fenômeno, é necessário considerar que a construção do gênero se sobrepõe aos fatores biológicos, e estabelece uma ligação mais coerente com as práticas e representações sociais do indivíduo do que com seus órgãos sexuais.

Para Santana (2016) as questões de gênero não se restringem apenas às características biológicas, tornando o debate sobre o tema uma importante ferramenta política, a fim de despertar indagações sobre as diferentes formas de constituir a identidade do indivíduo. O gênero não está necessariamente ligado à genitália de nascença, e sim, com as formas com que o indivíduo se apresenta em sociedade (Bento, 2017), por isso, conceituá-lo pode ser uma tarefa caótica, uma vez que sua construção é compreendida como um processo, dotado de variantes que interferem no seu desenvolvimento, $\mathrm{e}$ não como um resultado biologicamente antecipado (Moura \& Lopes, 2017). Sabe-se que, ao abordar questões relacionadas a esta temática, faz-se necessário adotar uma interpretação subjetiva, de modo a considerá-la como um tópico repleto de contrastes e complexidades que se modificam com regularidade, assim como a sexualidade, que não possui constância e se manifesta conforme o desejo de cada indivíduo.

Por isso, ao pensar em gênero, deve-se analisá-lo como um agente propositor de mudança que busca ressignificar a atribuição dos papéis sociais entre os sexos na sociedade (Oliveira, 2011), sabendo, portanto, que são as práticas e representações sociais que posicionam o sujeito em uma relação entre masculinidade e feminilidade (Barcellos, 2017). A relação entre masculino e feminino é construída a partir do modo como nossas características identitárias se exteriorizam no mundo, ou seja, a expressão dos nossos modelos discursivos e culturais constituem a expressão dos gêneros (Butler, 2003). Para a autora, o gênero é culturalmente construído, consequentemente não é resultado nem do sexo atribuído ao nascimento e nem tampouco aparentemente imutável quanto o próprio sexo.

Entretanto, a sociedade passou a estabelecer que as definições de gênero devessem ser usadas unicamente para sentenciar as diferenças anatômicas entre os indivíduos, por isso, é costumeiro relacionar orientação sexual, sexo biológico e gênero (Santos, Ramos, Silva \& Magrini, 2018). Por exemplo, o nascimento de uma criança pertencente ao sexo feminino gera uma expectativa de ordem social em relação ao seu gênero feminino e a sua heterossexualidade, partindo do pressuposto que este cenário é considerado o ideal pela sociedade 
(Butler, 2003). Contudo, existem indivíduos que não se enquadram nos padrões heteronormativos culturalmente estabelecidos pela sociedade e não se reconhecem em nenhuma das estruturas de gênero vigentes criadas por ela. O que essas pessoas desejam é, sobretudo, serem reconhecidas como integrantes do gênero com o qual se identificam (Pedra, Sousa, Rodrigues \& Silva, 2018).

Para tentar se integrar em sociedade, o indivíduo é forçado a se adequar ao padrão de gênero hegemônico, o cisgênero, resultando quase sempre em significativas renúncias de privação social e de direitos indispensáveis (Rondas \& Machado, 2015). Quando estes indivíduos não se encaixam nos padrões cisgêneros impostos pela sociedade, são automaticamente inferiorizados, e surge então a ilusória autoridade do sujeito tido como "normal" para com o sujeito tido como diferente (Pedra et al., 2018). Deste modo, institui-se um processo cultural de marginalização compulsória, onde o indivíduo que não seenquadraaopadrão degêneroheteronormativo é forçado a viver e conviver à margem da sociedade, em razão da sua individualidade. Esses sujeitos são conhecidos como transexuais.

O termo "trans", em geral, significa mudança, trânsito ou transformação de parâmetros já estabelecidos (Almeida \& Vasconcellos, 2018). Entende-se por transexual o indivíduo que possui incompatibilidade entre sua identidade de gênero e seu sexo biológico, podendo, ou não, realizar intervenções cirúrgicas para readequar seu órgão sexual, a fim de se aproximar fisicamente a expressão do seu gênero. Em suma, a transexualidade pode ser interpretada como um sentimento que incorresponde às expectativas definidas socialmente para com o sexo anatômico do indivíduo, podendo submeter-se a tratamentos cirúrgicos para adequar seu corpo a sua condição identitária (Souza \& Bernardo, 2014).

Bento (2017) afirma que o transexual, de modo geral, não apresenta nenhum problema biológico, mas a cirurgia pode se mostrar, em alguns casos, como a única possibilidade de encontrar sentido para sua existência. O processo de resignação sexual varia de acordo com a necessidade particular do indivíduo. Para uma parte da comunidade, realizar modificações no corpo físico pode proporcionar uma maior adequação a sua identidade de gênero, possibilitando certo equilíbrio entre a saúde física e mental, embora este procedimento não seja considerado um fator determinante para a afirmação da sua identidade.

Sabe-se que a afirmação da identidade de gênero do indivíduo está ligada à sua própria autodeterminação, ou seja, cabe ao próprio indivíduo se auto definir e consequentemente auto afirmar sua própria identidade (Bento, 2017). Em geral, as pessoas transexuais anseiam em serem aceitas e integradas socialmente ao gênero com o qual se identificam, sabendo assim que o critério que define se uma pessoa é transexual ou não é condicionado unicamente sua identidade (Ministério dos Direitos Humanos [MDH], 2018). Assim sendo, os indivíduos trans começam a adotar hábitos, trejeitos e comportamentos característicos do gênero ao qual se sentem pertencer, desempenhando seus papéis sociais mediante a forma pela qual se reconhecem (Barcellos, 2017).

Entretanto, estes indivíduos sofrem enormes pressões sociais para corresponder às expectativas definidas ao seu gênero e, frequentemente, vivenciam situações de exclusão, ocasionando grande sofrimento psicológico e significativas privações de convívio (Souza, 2012). Para a autora, espaços como o trabalho e a escola não se encontram preparados para lidar com a diversidade, mesmo sabendo que são decisivos para o surgimento e a perpetuação de estigmas e preconceitos. Sabe-se que a exclusão social é uma realidade vivenciada por esse grupo que, de algum modo, é restringido do acesso ao trabalho, restando apenas subempregos informais e em casos isolados, com raros registros de trabalho (Carvalho, 2006).

\section{A Mulher Transexual E Seus Dilemas Cotidianos}

O trabalho, além de satisfazer as necessidades 
básicas do indivíduo, representa uma espécie de identidade social que contribui significativamente para determinar o posicionamento do sujeito em sociedade (Souza \& Bernardo, 2014). É por meio dele que a identidade humana se forma, transformando a nós mesmos, as pessoas que nos cercam e o nosso mundo(Jesus, 2018). Ele tem oobjetivo decontribuir para que o indivíduo desenvolva suas habilidades e encontre um significado para a sua existência na sociedade (Souza, 2012). Contudo, embora seja considerada uma prerrogativa constitucional e uma das principais garantias fundamentais dos direitos universais, nem todos os indivíduos conseguem ter acesso ao trabalho de forma igualitária, sobretudo os grupos marginalizados, seja por questões ligadas a qualificação ou ao preconceito.

Em decorrência das suas individualidades, muitas mulheres transexuais enfrentam dificuldades na busca por emprego formal, seja devido à baixa escolaridade, fruto do processo de exclusão, ou a sua condição de gênero (Licciardi, Waitmann \& Oliveira, 2015). Usualmente, as mulheres transexuais são compreendidas como um subgrupo específico da população de mulheres, ligado a comunidade LGBTQIAP+ que, como tal, merecem ser compreendidas a partir de suas diferenças, a fim de evitar que se tornem invisibilizadas (Pedra et al., 2018). Considera-se mulher transexual o indivíduo que ainda possui traços e fisionomia masculina, possíveis de serem identificados na voz, no corpo e trejeitos, mas que não se reconhece e/ou se enquadra nos conceitos socialmente atribuídos ao gênero de nascimento (Gonçalves, 2019). Ainda segundo o autor, a mulher transexual distorce as características associadas ao seu gênero biológico com a intenção de formular, involuntariamente, um novo conceito do que seja considerada mulher.

Esses sujeitos também podem ser compreendidos como personagens que não se adaptam ao sexo designado anatomicamente, podendo chegar, em alguns casos, a realizar uma adequação corporal que busque assemelhar-se a feminilidade (Conselho Nacional de Combate à Discriminação [Conselho], 2004). De certo modo, a alteração de suas características físicas, na maioria dos casos, está relacionada à cirurgia de readequação sexual, que proporciona não somente o reconhecimento íntimo da sua identidade, mas também uma possível aceitação social (Barcellos, 2017). Ao se referir às transexuais, atribui-se as mesmas uma espécie de "carga extra”, que se intensifica em decorrência da construção social de ideal feminino, que se contradiz nos traços masculinos ainda existentes, fugindo aos padrões estabelecidos pela sociedade (Carvalho, 2006).

Segundo o autor, a sociedade costuma ser tão imperdoável para com aqueles que fogem a normatização hegemônica, que acabam interferindo no seu cotidiano, de modo a limitar suas liberdades, suas escolhas e suas oportunidades. Essa cultura heteronormativa, que nega a identidade de gênero das transexuais, desencadeia um afastamento social precoce, delimitando indiretamente os espaços que devem ou não ser ocupados, incluso o acesso ao mercado de trabalho (Gonçalves, 2018). Acuadas, a maioria das transexuais são forçadas a conviver com o desprezo das pessoas que não as reconhecem tampouco aceitam suas identidades de gênero, tornando sua inclusão em sociedade um processo cada vez mais difícil e complexo (Licciardi, et al., 2015).

Isso porque as transexuais não são consideradas como "mulheres", além de serem descriminadas e associadas a posturas tidas socialmente como "reprováveis", por isso, encontram inúmeras resistências para acessar o mercado de trabalho formal (Almeida \& Vasconcellos, 2018). Recusadas em função de suas individualidades de gênero, essas pessoas buscam na informalidade sua subsistência, de modo a tornar a prostituição e a prática de pequenos delitos em hábitos, o que também as coloca sob jugo da sociedade (PEDRA et al., 2018). São frequentemente associadas à violência, ao tráfico de drogas e outras situações inusitadas, graças ao empenho dos noticiários responsáveis por nutrir os destaques relacionados a prisão, assassinatos e qualquer escândalo em que são envolvidas (Rondas \& Machado, 2015). 
De modo consequente, uma parte das transexuais associa-se a marginalidade como um método de proteção e sobrevivência econômica, e estabelecem, contra sua vontade, uma dependência direta com as organizações criminosas e redes ilegais de tráfico e prostituição, que pode resultar, na maioria das vezes, no cárcere ou em morte. $\mathrm{O}$ estudo da Associação Nacional de Travestis e Transexuais do Brasil (ANTRA, 2018) relata que no ano de 2018 ocorreram, ao todo, cerca de 163 assassinatos de pessoas trans no território brasileiro, sendo que 158 eram travestis e mulheres transexuais.

"Segundo o relatório publicado pela Trans Murder Monitoring (TMM, 2018, Comunicado à Imprensa), conhecida como uma organização internacional de monitoramento dos casos de transfobia ao redor do mundo, de Janeiro de 2008 a Junho de 2016 cerca de 2.190 transexuais foram mortos, sendo que $39,6 \%$ dos casos foram registrados somente no Brasil”. Em geral, transfobia é o tipo específico de preconceito, discriminação e/ ou violência praticada contra pessoas transexuais em função da sua identidade de gênero, mas também funciona como fundamento guarda-chuva, que abarca todos os demais preconceitos vivenciados por esses indivíduos (Almeida \& Vasconcellos, 2018). Em geral, manifesta-se em forma de exclusão, agressões (físicas, emocionais e psicológicas) ou mesmo em assassinato, e também com uma preocupação excessiva do outro em garantir que as pessoas transexuais sigam os papéis sociais associados culturalmente ao seu sexo biológico (MDH, 2018).

De acordo com pesquisa mais recente, também produzida pela TMM no ano de 2018, o país lidera o ranking de assassinatos, sendo responsável por $45,2 \%$ das mortes (TMM, 2018, Comunicado à Imprensa). Além da alta taxa de mortalidade, a população trans ainda convive com outros índices considerados alarmantes, a exemplo da baixa taxa de ocupação de vagas no mercado e a evasão escolar relativa aos anos da educação básica (Pedra et al. 2018).
A ANTRA (2018) relata que, cerca de 90\% das travestis e mulheres transexuais ainda utilizam a prostituição como principal fonte de renda, devido ao baixo nível de escolaridade e ao preconceito, que dificulta sua inserção no mercado formal de trabalho. A culpa pela situação precária das pessoas trans não é do trabalho sexual em si, ele é apenas um sintoma da transfobia estrutural presente de maneira sistemática na sociedade (Jesus, 2018). Em casos excepcionais, as oportunidades de trabalho formais fora da prostituição, concentram-se nos serviços gerais, limpeza, alimentação e, em maior grau, nos salões de beleza (Carvalho, 2006). "Em média, 50,8\% das trans complementam sua renda atuando como cabelereiras, todavia 49,2\% ainda ocupam posições que dificilmente possibilite valorização ou crescimento profissional, atuando como cozinheira, empregada doméstica dentre outros postos de trabalho, conforme os resultados do Projeto Trans do Núcleo de Direitos Humanos e Cidadania LGBT da Universidade Federal de Minas Gerais" (NUH/UFMG, 2015).

Embora as discussões sobre gênero e sexualidade tenham se intensificado nos últimos anos nos diversos espaços sociais, sobretudo no âmbito acadêmico, a maioria dos indivíduos trans ainda vivem no extremo da sociedade em razão da sua individualidade, eem raras exceções ocupam espaços no mercado de trabalho formal que lhes garanta protagonismo e visibilidade. A falta de qualificação profissional associado ao baixo nível de escolaridade, fruto da evasão escolar oriunda da discriminação, são considerados fatores predominantes que reafirmam o cenário de segregação social entre as transexuais, impactando diretamente sua trajetória profissional.

De acordo com o NUH/UFMG (2015), apenas $2,2 \%$ de uma pequena amostra de transexuais possuem nível superior e $59,4 \%$ ainda não concluíram o ensino médio. Segundo a Associação Brasileira de Lésbicas, Gays, Bissexuais, Travestis e Transexuais (ABGLT, 2016, p.28), um pouco mais de $60 \%$ dos estudantes LGBTQIAP+ se sentem inseguros nas instituições de ensino em razão da sua 
identidade de gênero ou orientação sexual. Embora também seja considerado um direito constitucional assegurado pelo Estado, o acesso e a permanência em ambientes educacionais se tornam um obstáculo cotidiano para as minorias sociais, sobretudo para a comunidade trans, que lida diariamente com o preconceito nocivo no contexto escolar. Presumese que o problema não é de acesso à educação, mas de dificuldades de garantir a permanência na escola, especialmente quando o indivíduo trans começa a performar sua identidade de gênero (Almeida \& Vasconcellos, 2018).

Quando a rejeição se faz presente na família, a transexual é entregue a rua e associam-se as formas tidas como não convencionais de ganha a vida, estando sujeitas a situações que podem lhe acarretar doenças e morte social e física (Rondas \& Machado, 2015). A participação da família pode ser decisiva para ajudar na superação das dificuldades encontradas na escola, porém, infelizmente acontecer na minoria das vezes (Souza \& Bernardo, 2014). O discurso de Amanda, 32, atendente de call center, elucida bem o dilema existente entre a relação da família e a escola:

Quando criança e adolescente sofri bastante bullying. Não tive apoio familiar. Família é a base para muitas pessoas, se não houvesse tanto preconceito com certeza a vida de muitas travestis e mulheres transexuais seriam diferentes. No meu caso atrapalhou bastante porque abandonei uma graduação por falta de apoio financeiro que poderia ser resolvido com a ajuda dos meus pais, daí acabei conhecendo o mundo da prostituição.

A escola, como espaço de formação, reproduz as ideologias e saberes dominantes excluindo assim outros saberes e formas de conhecimento, além de perpetuar práticas vigentes na sociedade, (Campos \& Pereira, 2018) de modo a considerar a discriminação e o preconceito parte desse processo hegemônico. Segundo a ABGLT (2016, p.30), quase um terço $(31,7 \%)$ dos estudantes LGBTQIAP+ afirmaram ter faltado na instituição educacional pelo menos um dia ao mês porque se sentiam inseguros ou constrangidos. Entre as principais causas relacionadas ao abandono escolar entre as transexuais, de acordo com o destacam-se o trabalho precoce $(25 \%)$, o preconceito sofrido na escola $(18,2 \%)$ e a violência homofóbica $(9,9 \%)$, para além de uma agressão física, seus cotidianos são permeados por desrespeito ao uso do nome social, dificuldades de acesso aos banheiros femininos, relações hostis com professores, colegas e outros profissionais da escola que acabam por diariamente desmotivar a sua permanência no sistema de ensino" (NUH/UFMG, 2015).

No caso de Melyssa, 40, operadora de caixa de hipermercado, fica evidente que os fatores que quase definiram sua evasão escolar foram associados ao preconceito vivenciado dentro do ambiente educacional, que, por sua vez, são compreendidos como reflexos dos comportamentos dominantes na sociedade:

Sofri muito preconceito e tive que me excluir das brincadeiras e vivências escolares para que eu pudesse não ter muitos problemas. Sempre estava com as meninas que me entendiam, mas sempre "haviam" piadinhas de mau gostos até mesmo xingamentos. Sempre continuei porque sempre gostei de estudar e eu sofri alguns "bules", como no banheiro no qual eu tive que ficar sem ir ao banheiro durante um tempo por medo de sofrer algum tipo de assédio ou algo pior. Na minha época não tinha a questão do nome social, então era sempre muito difícil ser chamado pelo RG.

Esse panorama se estende por todas as séries escolares, principalmente nos anos iniciais do ensino médio, onde os episódios de bullying se acentuam e se materializam em razão das modificações corporais e da formação dos traços de personalidade, convertendo-se em um processo vicioso de exclusão. "Segundo o relatório que trata sobre a violência LGBTQIAP+ no Brasil, organizado 
pela Clínica de Políticas de Diversidade da Faculdade de Direito da Fundação Getúlio Vargas de São Paulo (FGV/SP), o preconceito escolar, se não combatido da forma correta e na idade adequada, provoca efeitos perversos que impactam para sempre a trajetória destas pessoas" (FGV/SP, 2020, p. 20). Para Nathália, 24, psicóloga e servidora pública, a luta para permanecer na escola estava relacionada à construção sua identidade, mesmo que ainda não a tivesse constituída. A assessora de cultura diz:

Sofri muita discriminação. Ao terminar os estudos que fui entender o que era ser trans. Continuei meus estudos porque morava próximo da escola e acabei aprendendo a me defender só. O preconceito a nível escolar sempre esteve presente, mas eu o ignorei porque naquele momento, por mais segura que eu estivesse da minha "diferença", eu ainda não sabia quem era e precisava descobrir. Só a educação iria me proporcionar isso.

Em sua maioria, os indivíduos transgêneros sentem-se pressionados a abandonar os estudos para evitar ainda mais sofrimentos ocasionados pelo preconceito presente nos ambientes educacionais (Souza \& Bernardo, 2014). De acordo com as autoras, supõe-se que exista um ciclo vicioso: o preconceito na infância prejudica a trajetória acadêmica e a falta de capacitação, junto com a exclusão ocasionada pelo preconceito social, deixa-lhes poucas opções de trabalho. Assim sendo, a maioria absoluta das transexuais enfrenta dificuldades ao tentar se inserir no mercado, mesmo nas formas mais precárias trabalho (Kaffer, Ramos, Alves \& Tonon, 2016). O corpo, por sua vez, também pode ser considerado um elemento que dificulta a inserção de mulheres transexuais no mercado de trabalho devido as suas próprias peculiaridades, presentes na voz e em alguns traços físicos (Almeida \& Vasconcellos, 2018).

Segundo as autoras, o ser transexual "está estampado na cara”, sendo algo que, em geral, não se pode esconder, uma vez que sua identidade de gênero é vivenciada de forma mais ostensiva, estando, de algum modo, marcada em seu corpo, nos trejeitos e/ou nos comportamentos sociais. O preconceito já se materializa no momento pré-contratual, sabendo que as identidades de gênero não são "ocultadas" ou "omitidas" de forma direta, mas se apresentam na vida desses sujeitos, seja nas suas performances ou na fisionomia (Menezes, Oliveira \& Nascimento, 2018). De acordo com os autores, as organizações podem utilizar de questões ligadas as suas características sexuais para impedir, excluir, limitar ou dificultar o acesso e a permanência desses indivíduos no mercado de trabalho em função da sua identidade de gênero.

Em prática, as transexuais que buscam se integrar no mercado podem gerar conflitos, mesmo que de forma involuntária, seja pela fisionomia ou pelo comportamento, porque "desafiam a normatividade" ao tentar ocupar espaços que não sejam ligados à marginalidade (Gonçalves, 2019). De acordo com o autor, só de realizar tentativas como essa, a mulher trans rompecomos estigmas associados à delinquência e, ao mesmo tempo, provoca, na sociedade, possíveis discussões sobre estratégias de inclusão voltadas à própria comunidade. Para esta população, se inserir no mercado não se trata apenas do acesso ao emprego, mas de poder desenvolver seu potencial profissional, sem entraves à carreira, com tratamento digno e liberdade para se expressar sem constrangimentos ou repressões superiores (Organização Internacional do Trabalho [OIT], 2015).

Sabe-se que as discussões que buscam a inclusão de pessoas transexuais nos diversos meios sociais, em destaque para mercado de trabalho, são cada vez mais comuns no âmbito internacional, entretanto ainda são consideradas emergentes no Brasil (Santos et al., 2018). Para Jesus (2018) são pouquíssimas as iniciativas existentes que buscam a inclusão de pessoas trans no mercado. Entre as escassas iniciativas que se dedicam a promover a inserção de transexuais no mercado de trabalho, destaca-se o programa Transcidadania, desenvolvido e mantido pela prefeitura da cidade de São Paulo, por meio da Secretaria de Direitos Humanos e Cidadania e 
o site Transempregos, destinado exclusivamente ao anúncio de vagas de emprego para pessoas transexuais e travestis. Em suma, o programa Transcidadania proporciona a reintegração do indivíduo em sociedade, de modo a facilitar o acesso aos serviços públicos essenciais e o cumprimento dos direitos e garantias fundamentais, ofertando capacitação técnica profissional, acompanhamento de saúde especializado, combate a evasão escolar dentre outros objetivos que buscam, em conjunto, promover o pleno exercício da cidadania para esses indivíduos.

O TransEmpregos, por outro lado, pode ser considerado uma ferramenta virtual acessível e gratuita que reúne recrutadores de empresas parceiras e potenciais candidatos as vagas ofertadas. Em geral, a iniciativa virtual, idealizada por lideranças do próprio movimento trans, busca promover o acesso ao mercado de trabalho formal para travestis e transexuais de uma maneira inovadora, prática e inclusiva. Contudo, embora existam algumas poucas iniciativas que proponham a inclusão de pessoas trans no mercado, ainda é muito cedo para afirmar que as organizações, de modo geral, estejam preparadas minimamente o suficiente para lidar adequadamente com as individualidades desses sujeitos.

Isso ocorre devido ao fato de que grande parte das empresas ainda adotam, em suas políticas internas cotidianas, práticas e costumes heteronormativos que consequentemente tendem a suprimir as tímidas tentativas que buscam valorizar a diversidade no ambiente de trabalho, com o intuito, mesmo que involuntário, de preservar uma suposta e frágil superioridade hegemônica em relação às diferenças. Em síntese, a sociedade, em sua maioria constituída por indivíduos heterossexuais, tende a se afastar de minorias como o caso das transexuais por medo dos estigmas, contribuindo para que essa parcela da própria sociedade seja submetida a condição invisibilidade (Kaffer et al., 2016).

\section{Resultados E Discussões}

Na perspectiva das entrevistadas, a ausência de mulheres transexuais no mercado de trabalho formal se resume, sobretudo, a dois pontos principais: a negligência do Estado e o despreparo das organizações. Nos últimos anos, embora fossem registrados alguns avanços por parte do segundo setor ao lidar com o tema, através de campanhas de valorização da diversidade e estratégias de inclusão no ambiente corporativo, poucas políticas públicas foram criadas com o objetivo de trabalhar a empregabilidade e oportunizar o acesso ao mercado de trabalho para pessoas trans. Para Jesus (2018) o Estado brasileiro precisa se responsabilizar pela ausência dessas políticas públicas que garantam trabalho formal para a população trans, já que as escassas iniciativas existentes partem das próprias pessoas trans.

Para criar uma política pública com esse recorte é preciso reconhecer as identidades de gênero e propor ações específicas direcionadas para as mulheres trans, de modo a buscar do Estado uma adequação das políticas públicas às suas realidades (Pedra et al., 2018). Entretanto, segundo os autores, a atuação do Estado e de suas instituições é superficial, porque não garantem o pleno exercício da cidadania, tampouco o respeito à dignidade da pessoa humana, uma vez que se baseiam em compreensões retrógradas sobre o assunto. Embora o Estado realize consideráveis avanços sobre o tema, a exemplo do uso do nome social e o reconhecimento à identidade de pessoas trans e travestis, ele ainda não é capaz de garantir sua efetividade e sequer sua correta aplicação, devida a falta de instrumentos de controle e/ou fiscalização que atestem sua eficácia.

Para solucionar esse impasse, é preciso construir uma política de empregabilidade trans com amplitude nacional e com a participação efetiva da própria comunidade, por meio dos movimentos sociais e das entidades de representação. Essas, por sua vez, devem envolver-se ativamente desde o processo de criação até a fiscalização dessas 
políticas, tentando transmitir ao Estado, através dos relatos de suas vivências cotidianas, as principais dificuldades enfrentadas pela comunidade no dia a dia ao tentar se inserir no mercado formal, traçando políticas públicas que colaborem, de fato, para uma transformação social. Não satisfeito, para obter algum êxito em algum momento, é necessário adotar uma postura mais enfática em relação ao Estado, exigindo dele o cumprimento de metas e compromissos para com a comunidade e suas entidades. É preciso que se tenha um Estado Interventivo frente aos vários problemas de ordem social (Menezes et al., 2018).

Essas metas devem incluir prazos e investimentos necessários que precisam estar estabelecidos dentro das próprias políticas, formuladas em conjunto com a comunidade, classificando-as por prioridades, de acordo com as suas necessidades mais emergentes da população trans. Contudo, entre a lei e as práticas cotidianas há uma significativa lacuna de contradições, sabendo que o mesmo Estado que reconhece o direito a identidade de gênero de pessoas trans é o mesmo que as desampara quando mais necessita (Bento, 2014). Para Nathália "a maior barreira é a falta de políticas públicas que garantam o trabalho formal as mulheres trans. As empresas, quando vão nos contratar, atentam-se aos paradigmas e não permitem que tenhamos um acesso a um trabalho digno.”

A fala de Melyssa, ao ser questionada sobre a ausência de mulheres transexuais no mercado de trabalho, posiciona o Estado e a sua inércia como fatores determinantes para perpetuação dos estigmas associados à marginalidade. De acordo com ela, o poder público poderia exercer o papel de protagonista no processo de inserção, entretanto, por motivos ainda desconhecidos, não o faz. Melyssa diz:

$\mathrm{Eu}$ acredito que a maior dificuldade que as travestis e transexuais enfrentam é o preparo a competição, digo, a capacitação profissional. Talvez por não "ter" condições para isso em um outro momento ou pelo fato de não ter conseguido emprego em relação a identidade de gênero. Mas, de qualquer jeito, o poder público precisava entender que essas pessoas deveriam estar inseridas nesses espaços. Talvez “ter” cotas para concursos públicos e assim oportunizar a essas pessoas, que também não tiveram condições de estar no contexto escolar, a estarem inseridas em alguma atividade, seja como servidor público. Oferecer projetos, como o Ministério Público de Goiás que "dá” capacitação profissional para as pessoas em situação de vulnerabilidade. Acredito que muitas trans gostariam de ter oportunidade no mercado de trabalho, sendo respeitada como pessoa trabalhadora e não sendo vista como uma pessoa trans. Esse seria o primeiro passo, pelo poder público.

De forma complementar, o relato de Amanda atribuí ao preconceito a posição de destaque entre as causas determinantes para a carência de mulheres trans nos ambientes corporativos. Em seu discurso, Amanda também reitera que o Estado deveria intervir nessa questão e, sobretudo, oferecer mecanismos que pudessem preservar a dignidade humana da sua própria comunidade. Amanda diz:

É uma questão delicada que engloba geral e não somente a área educacional ou profissional. O preconceito deve ser abolido, pessoas são pessoas, devem ser respeitadas e haver equidade, direitos e oportunidades iguais. Inserção sem rótulos de gênero e/ou orientação (condição) sexual. O poder público deve intervir, pois é uma questão de direitos humanos. A parte mais afetada entre travestis e transexuais é a dignidade humana. Se houvesse igualdade e respeito, aí sim, muitas travestis e transexuais gostariam de ter um emprego formal.

Contudo, a inércia do Estado em relação às políticas públicas não é o único fator que influencia diretamente na escassez de mulheres trans no mercado. A cultura sexista, presente em abundância 
no mercado de trabalho, torna, em muitas ocasiões, o acesso ao emprego algo inalcançável para as transexuais (Pedra et al., 2018). A hostilidade, a chacota, o assédio, o preconceito disfarçado de abuso de autoridade e a remuneração podem ser considerados fatores que contribuem diretamente no baixo índice de mulheres transexuais no mercado de trabalho (Rondas \& Machado, 2015). Além disso, as pessoas heterossexuais no ambiente de trabalho tendem a se afastar de minorias por medo dos estigmas, contribuindo para que essa parcela da sociedade seja submetida à condição de invisibilidade constante (Kaffer et al., 2016). Melyssa, embora esteja empregada em uma rede de hipermercados queliderainiciativas de inclusão para minorias sociais no país, já sofreu na pele os efeitos do preconceito materializados em forma de assédio e constrangimentos no ambiente profissional. Em sua fala, diz:

Eu sempre sofri assédio sexual por parte dos colegas. Talvez não pelo fato da minha identidade de gênero, mas talvez pelo fato do corpo que eu tenho...uma certa "beleza". Isso atraia as pessoas, e atraí até hoje. O que eu sempre sofri também foram as piadinhas do tipo: "Como você tem coragem?" Mas isso nunca acontecia na minha frente, eu sempre ficava sabendo. Era uma discriminação e um preconceito meio que velado.

Amanda relata uma situação ainda mais delicada que sintetiza o despreparo das organizações e de seus colaboradores ao lidar com mulheres transexuais. Depois deste acontecimento, segunda ela mesma, sua intimidade foi violada de tal maneira que originaram sequelas ainda não remediadas até hoje. Ela relata:

Já sofri assédio, humilhação, constrangimento e violência (verbal, moral e psicológica). Trabalhei na Atento em 2012 e foram os piores meses de minha vida. E, para completar, fui demitida injustamente. Essa ferida cicatrizou, mas as marcas do que passei infelizmente sempre existirão. Em 2015 trabalhei em outra empresa de callcenter. Eu era respeitada pela empresa e pelos meus superiores, porém, minha genitália era muito questionada entre colegas de trabalho. Nenhum lugar está preparado de verdade.

Para a maioria das transexuais, o preconceito e a discriminação que sofrem em relação ao mercado de trabalho está diretamente ligado à falta de informações e o despreparo, por parte das organizações, ao lidar com aspectos relacionados à transexualidade (Licciardi, et al., 2015). Para os autores, questões como a compreensão sobre a da identidade de gênero, respeito à diversidade sexual e estratégias de inclusão devem ser problematizadas para que possamos alcançar uma sociedade mais próxima possível do que é previsto por lei. Em suma, os desafios para inserir transexuais no mercado partem desde o processo de recrutamento e seleção até o convívio cotidiano, que pode ser influenciado por fatores como a transfobia e as dificuldades de aceitação efetiva do nome social (Teixeira, 2019).

Em sua última fala, Melyssa exemplifica a relação existente entre transexuais e o mercado de trabalho. Logo ao tentar estabelecer o primeiro contato em busca de emprego, depois de concluir sua transição, se depara com um cenário indesejável, onde mercado e empregadores negam oportunidades trabalho baseando-se nos estigmas sociais culturalmente associados à comunidade. Ela conclui que:

Procurei serviço e não encontrei pelo fato de não ter um nome que condiz com a minha identidade de gênero ou até mesmo por não ter o reconhecimento por parte dos empregadores de que a minha identidade nada influenciaria na minha capacidade. Acredito que o que mais afasta as pessoas trans do mercado de trabalho é o empregador "sentir" que essa pessoa não é capaz de desenvolver qualquer função e sempre estigmatizar que pessoas trans são sempre envolvidas a prostituição, sempre "barraqueiras" ou algo vinculado necessariamente ao sexo. Por isso, não tive outra saída, decidi viver da prostituição até fazer a retificação de registro e minha cirurgia de redesignação sexual para que eu pudesse me sentir completa comigo mesma e poder 
enfrentar o mercado de trabalho. Depois disso, sempre fui vista e respeitada como mulher cisgênero. $\mathrm{Na}$ empresa onde trabalho sou apenas mais uma funcionária e todos, inclusive meu supervisor, me tratam como tal.

Programas de cotas, capacitação e sensibilização dosfuncionários, por meio do respeito ao nomesocial e ao uso de espaços em comum conforme o gênero com o qual a pessoa se identifica, representariam um enorme avanço do tema nas organizações (Almeida \& Vasconcellos, 2018). Contudo, é importante ressaltar que o combate às várias formas de preconceito no ambiente de trabalho é um papel que compete não somente ao Estado, mas sim de uma ação conjunta das instituições empregatícias (Menezes et al., 2018).

Nesse sentido, para buscar soluções práticas que tornem o processo de inserção de mulheres trans no mercado algo cada vez mais possível, deve-se propor amplas discussões sobre o tema, de forma a enfatizar seus dilemas cotidianos e considerá-los como bases propulsoras das políticas públicas e das estratégicas de inclusão e combate ao preconceito no ambiente de trabalho. Os impactos e as transformações sociais que se buscam através do produto dessas discussões só serão alcançados com a participação protagonista desses indivíduos, de forma a considerar seus discursos como eixos centrais de todo o processo.

\section{Considerações finais}

A transexualidade de modo geral, embora seja conceituada como um comportamento identitário singular de determinados indivíduos, ainda é compreendida, para uma considerável parte da sociedade, como um tema subversivo associado à marginalidade. A necessidade de tratar o assunto como uma questão de ordem social ainda é visto como um problema recente. Constatou-se que, no caso das mulheres transexuais, predominase um processo de exclusão social baseado em um ciclo vicioso que tem origem na rejeição familiar, provocando a evasão escolar, tornando a informalidade e a prostituição métodos de sobrevivência. Esse processo involuntário é o que sustenta os estigmas sociais.

Antes de discorrer sobre os aspectos conclusivos da pesquisa, deduz-se que a marginalização social é umprodutoexclusivodasociedadeheteromormativa, que, entre outras funções, inviabiliza a ocupação de pessoas trans nos espaços sociais, incluso o ambiente corporativo. Buscou-se, por meio deste estudo, analisar a ausência de mulheres transexuais no mercado de trabalho formal em Goiás a partir de seus breves relatos de experiências de vida e profissionais junto à bibliografia pertinente ao tema. Os resultados apontaram para negligência do Estado e a incompetência das organizações do segundo setor.

Trata-se, sobretudo, de discutir com seriedade os problemas cotidianos que as transexuais enfrentam em relação ao mercado de trabalho e evidenciar, através de seus relatos, as deficiências estruturais presentes no mercado e no poder público ao lidar com o problema. Devem-se buscar respostas práticas capazes de criar condições de acesso ao trabalho de forma equitativa para pessoas trans, especialmente as travestis e mulheres transexuais, sabendo que esses indivíduos não se enquadram no modelo hegemônico condicionado pela sociedade.

É necessário construir mais do que apenas uma relação harmoniosa entre o Estado e o segundo setor em relação ao tema. Presume-se que ambos devem se empenhar ao máximo para desenvolver ações conjuntas capazes de criar, regulamentar, promover, executar e fiscalizar iniciativas que proponham a restauração da dignidade humana através do trabalho para mulheres transexuais.

Portanto, é imprescindível mantê-la e, ao mesmo tempo, envolver os sujeitos dessa pesquisa na construção desses caminhos, a fim de combater ostensivamente as práticas, condutas e comportamentos transfóbicos que impossibilitam às transexuais, em proporções cada vez maiores, 
de acessar ao mercado de trabalho formal sem prejuízos, ataques ou hostilidade a sua identidade de gênero.

Em suma, espera-se que esse estudo contribua para difundir, mesmo que superficialmente, os problemas cotidianos das mulheres transexuais, de modo a tornar suas experiências de vida e suas batalhas diárias cada vez mais discutidas e compreendidas pela academia e sociedade.

\section{Referencias}

Almeida, C. B. \& Vasconcellos, V.A. (2018). Transexuais: transpondo barreiras no mercado de trabalho em São Paulo. Revista Direito FGV, 14(2), 302-333. doi: 10.1590/2317-6172201814

Associação Brasileira de Lésbicas, Gays, Bissexuais, Travestis, Transexuais e Intersexos. (2016). Pesquisa Nacional sobre o Ambiente Educacional no Brasil 2015: as experiências de adolescentes e jovens lésbicas, gays, bissexuais, travestis e transexuais em nossos ambientes educacionais. Recuperado de http://static.congressoemfoco.uol.com.br/2016/08/IAEBrasil-Web-3-1.pdf.

Associação Nacional de Travestis e Transexuais. (2018). Mapa dos assassinatos de travestis e transexuais no Brasilem 2017. Recuperadoem:https://antrabrasil.files.wordpress.com/2018/02/ relatc3b3rio-mapa-dos-assassinatos-2017-antra.pdf

Barcellos, C. (2017). Demitindo Preconceitos. Goiânia, Brasil: Memória LGBT.

Bento, B. (2014). Nome social para pessoas trans: cidadania precária e gambiarra legal. Contemporânea - Revista de Sociologia da UFSCar, 4(1), 165-182. Recuperado de http://www. contemporanea.ufscar.br/index.php/contemporanea/article/view/197/101

Bento, B. (2017). A reinvenção do corpo: sexualidade e gênero na experiência transexual. Salvador, Brasil: Editora Devires.

Butler, J. (2003). Problemas de gênero: feminismo e subversão da identidade. Rio de Janeiro, Brasil: Editora Record.

Campos, G. A. \& Pereira, M. C. (2018). Cursinho Prepara Trans: possibilidade de articulação entre gênero e educação popular. Revista Educação Popular, 17(3), 183-194. doi: 10.14393/ REP-v17n32018-rel01

Carvalho, E. R. (Agosto de 2006). "Eu quero viver de dia"- Uma análise da inserção das transgêneros-no mercado de trabalho. In C. S. Wolff., M. Fáveri, e T. R. O Ramos, (Presidência), VII Seminário Fazendo Gênero. Florianópolis, Brasil. Recuperado de http://www.wwc2017.eventos.dype.com.br/fg7/ artigos/E/Evelyn_Carvalho_16.pdf 
Clínica de Políticas de Diversidade da Faculdade de Direito da Fundação Getúlio Vargas de São Paulo. 2020. A VIOLÊENCIA LGBTQIA+ NO BRASIL. Recuperado de https://direitosp. fgv.br/sites/direitosp.fgv.br/files/arquivos/a_violencia_lgbtqia_no_brasil.pdf

Conselho Nacional de Combate à Discriminação (2004). Brasil Sem Homofobia: Programa de combate à violência e à discriminação contra GLTB e promoção da cidadania homossexual. Recuperado de https://bvsms.saude.gov.br/bvs/publicacoes/brasil_sem_homofobia.pdf

Fonseca, J. J. S. (2002). Metodologia da pesquisa científica. Fortaleza, Brasil: UEC.

Gerhardt, T. E. \& Silveira, D. T. (2009). Métodos de pesquisa. Porto Alegre, Brasil: Editora da UFRGS.

Gil, A. C. (2007). Como elaborar projetos de pesquisa. São Paulo, Brasil: Atlas.

Gonçalves, J. V. R. (Outubro de 2018). As barreiras sociais que afastam a população transexual na busca pela permanência no sistema educacional. In: V Congresso De Ensino, Pesquisa e Extensão da UEG. Congresso organizado pela Pró Reitoria de Pesquisa e Pós Graduação, Pirenópolis, Brasil. Recuperado de https://www.anais.ueg.br/index.php/cepe/article/ view/13310

Gonçalves, J. V. R. (Outubro de 2019). (Trans gredir): uma análise a cerca dos fatores sociais que dificultam o acesso da mulher transexual no mercado de trabalho formal. In S. Albernaz, XXIV Congresso Nacional de Administração (CONAD). Congresso organizado pela Associação Goiana de Administração (AGAD), Goiânia, Brasil. Recuperado de https://conad.adm. br/2019/wp-content/uploads/2019/09/02-2-13-transgredir-uma-anaxxlise-a-cerca-dos-fatores-sociais-que-dificultam-o-acesso-da-mulher-transexual-no-mercado-de-trabalho-formal.pdf

Jesus, J. G (2018). Trans tem "T" de trabalho. In Vasconcelos, $\mathrm{P}$ (Ed). Transresistência: histórias de pessoas trans no mercado formal de trabalho. São Paulo, Brasil: Editora Casa Flutuante. Recuperado de https://abraji-bucket-001.s3.sa-east-1. amazonaws.com/uploads/publication_info/details_file/
4f6ea59e-6ldl-45f4-ada6-0e80be7d8501/Transresist_nciae-book-ed2.pdf

Kaffer, K. K., Ramos, F. G., Alves, A. L. \& Tonon, L. (Outubro de 2016). A transexualidade e o mercado formal de trabalho: principais dificuldades para a inserção profissional. IV Congresso Brasileiro de Estudos Organizacionais. Congresso organizado pela Sociedade Brasileira de Estudos Organizacionais (SBEO), Porto Alegre, Brasil. Recuperado de https:// anaiscbeo.emnuvens.com.br/cbeo/article/view/52/44

Licciardi, N., Waitmann, G. \& Oliveira, M. H. M. (2015). A discriminação de mulheres travestis e transexuais no mercado de trabalho. Revista Científica Hermes, 14(2), 201-218. doi: 10.21710/rch.vl4iO.210

Lüdke, M. \& André, M. E. D. A. (1986). Pesquisa em educação: abordagens qualitativas. São Paulo, Brasil: EPU.

Menezes, M.S., Oliveira,A.C. \& Nascimento,A.P.L. (Abril de 2018). LGBT E MERCADO DE TRABALHO: Uma trajetória de preconceitos e discriminações. I Conferência Internacional de Estudos Queer (ConQueer), Sergipe, Brasil. Recuperado de https://editorarealize.com.br/artigo/visualizar/40228

Ministério dos Direitos Humanos. (2018). Manual Orientador Sobre Diversidade. Recuperado de https://bibliotecadigital. mdh.gov.br/jspui/handle/192/1325

Moura, R. G. \& Lopes, P. L. (Abril de 2017). Comportamento Organizacional frente a diversidade: A inclusão de travestis e transexuais no mercado de trabalho. XIV Simpósio de excelência em gestão e tecnologia (SEGeT). Simpósio organizado pela Associação Educacional Dom Bosco (AEBD), Resende, Brasil. Recuperado de https://www.aedb.br/seget/arquivos/artigos17/1182593.pdf

Núcleo de Direitos Humanos e Cidadania LGBT da Universidade Federal de Minas Gerais. 2015. Projeto Trans: Travestilidades e Transexualidades. Recuperado de http://www.nuhufmg. com.br/gde_ufmg/index.php/projeto-trans

Oliveira, P. C. (Novembro de 2011). A importância do ensino sobre questões de gênero na educação. II Seminário de Estágio da Licenciatura em Ciências Sociais. Seminário organizado pela 
Universidade Estadual de Londrina (UEL), Londrina, Brasil. Recuperado de http://www.uel.br/projetos/lenpes/pages/ arquivos/aOLIVEIRA\%20\%20Polyanna\%20Claudia.pdf

Organização das Nações Unidas no Brasil. (2018). Páginas trans: guia de acesso a direitos e serviços para pessoas trans. Recuperado de http://aliancalgbti.org.br/wp-content/ uploads/2020/08/16.-ONUBR-Cartilha-P\%C3\%Alginas-Trans.pdf

Organização Internacional do Trabalho. (2015). Promoção dos Direitos Humanos de pessoas LGBT no Mundo do Trabalho. Recuperado de https://unaids.org.br/wp-content/ uploads/2016/01/2015_ManualPromocaoDireitosLGBTTrabalho_PT_V2.pdf

Pedra, C. B., Souza, E. C., Rodrigues, R. V.A. \& Silva, T. S. A. (2018). Políticas públicas para inserção social de travestis e transexuais: uma análise do programa "transcidadania”. Revista de Ciências do Estado, 3(1), 170-199. Recuperado de https://periodicos.ufmg.br/index.php/revice/article/view/5091/3149

Rondas, L. O. \& Machado, L. R. S. (2015). Inserção profissional de travestis no mundo do trabalho: das estratégias pessoais às políticas de inclusão. Pesquisas e Práticas. Psicossociais, 10(1), 194-207. Recuperado de http://www.seer.ufsj.edu.br/ index.php/revista_ppp/article/view/Rondas\%2C\%20Machado/992

Santana, A. L. A. (2016). A vivência dos travestis em escolas e no ensino superior brasileiro: uma análise bibliográfica do período 2011-2015. Revista Científica UniFagoc - Multidisciplinar, 1(1), 99-111. Recuperado de https://revista.fagoc.br/index. php/multidisciplinar/article/view/105/85

Santos, C. C., Ramos, N. M., Silva, J. G. \& Magrini, V. O. (Agosto de 2018). TRANSGÊNEROS NO MERCADO DE TRABALHO. $29^{\circ}$ ENANGRAD: Gestão da Aprendizagem. O encontro é organizado pela Associação Nacional dos cursos de graduação em Administração (ANGRAD), São Paulo, Brasil.

Souza, H. A. (2012). O desafio do trabalho na vida cotidiana de mulheres transexuais. (Dissertação de Mestrado) - Pontifícia Universidade Católica de Campinas, São Paulo, Brasil. Recuperado de http://tede.bibliotecadigital.puc-campinas.edu. br:8080/jspui/handle/tede/302

Souza, H. A. \& Bernardo, M. H. (2014). Transexualidade: as consequências do preconceito escolar para a vida profissional. Revista Bagoas - Estudos gays: gêneros e sexualidades, 8(11), 157-175. Recuperado de https://periodicos.ufrn.br/bagoas/ article/view/6548/5078

Spink, P. K. (2003). Pesquisa de campo em Psicologia Social: Uma Perspectiva Pós-construcionista. Psicologia \& Sociedade, 15(2), 18-42. Doi: 10.1590/S0102-71822003000200003

Teixeira, B. F. (2019). Diversidade e inclusão nas organizações: o desafio da inclusão de pessoas transgênero no mercado de trabalho formal. (Monografia de Graduação). Universidade Federal do Rio De Janeiro, Rio de Janeiro, Brasil. Recuperado de https://pantheon.ufrj.br/bitstream/11422/12354/1/BFTeixeira.pdf

Trans Murder Monitoring. (2018). Comunicado à Imprensa do Dia da Memória Trans (TDoR) 2018. Recuperado de https:// transrespect.org/en/tmm-update-tdor-2018/

2020, Vol. 13(26) 33-50 @The Author(s) 2020 Reprints and permission: www.americana.edu.co http://publicaciones.americana.edu.co/index.php/pensamientoamericano/index 